* Pós-Doutor em Direito da Universidade de Lisboa. Doutor e Mestre em Direito pela PUC/ SP. Professor Titular do Mestrado e da Graduação em Direito da UNINTER. Diretor de Relações Internacionais do Instituto de Direito Constitucional e Cidadania (IDCC). Telefone: 41-99647-6766. E-mail: alexandrecoutinhopagliarini@ gmail.com

** Mestre em Direitos Humanos pela Universidade Tiradentes, Professor Universitário da Universidade Tiradentes em Alagoas, Faculdade Sete de Setembro em Paulo Afonso/Ba e Sociedade de Ensino do Nordeste - SEUNE, Advogado.

\section{A utilização da fazenda urbana Vertical Como Meio DE FOMENTAR A SUSTENTABILIDADE}

\author{
THE UTILIZATION OF THE VERTICAL URBAN FARM AS A MEANS \\ TO PROMOTE SUSTAINABILITY
}

\section{Alexandre Coutinho Pagliarini* Flávio Adriano Rebelo Brandão Santos ***}

Como citar: PAGLIARINI, Alexandre Coutinho. SANTOS, Flávio Adriano Rebelo Bandrão. A utilização da fazenda urbana vertical como meio de comentar a sustentabilidade. Revista do Instituto de Direito Constitucional e Cidadania, Londrina, v. 3, n. 1, p. 209-225, jan/jun. 2018. https://doi.org/10.48159/revistadoidcc.v3n1.pagliarini.santos

Resumo: Esta pesquisa tem por objetivo estabelecer novas formas de exercício do zoneamento urbano, com ênfase a fixar atividade socioeconômica através da difusão das fazendas verticais nos perímetros urbanos, cabendo ao Município promover políticas públicas no sentido de incentivar sua ocorrência, haja vista que se trata de uma técnica que além de estabelecer de um meio ambiente ecologicamente equilibrado, permite-se realizar o desenvolvimento humano. Entende-se que uma política pública de incentivo fiscal especialmente voltada a extrafiscalidade, permitia aos Municípios atrair empresas que tenham especialidade e domínio neste tipo de prática, cultivando: verduras, legumes e outras atividades agrícolas, por meio da técnica da plantação vertical, ao passo que estas serão obrigadas a inserir no seu insumo produtivo pessoas de baixa renda. De acordo com o artigo 170, da CF a função precípua do Estado, no que pertine a ordem econômica, é estabelecer um desenvolvimento da economia enfatizando a valorização do trabalho humano e na livre iniciativa, com a finalidade de assegurar uma coexistência digna entre a justiça social, a proteção ambiental em consonância com políticas públicas de impulso a economia. Logo, mostrase mais adequado incentivar os agentes econômicos no sentido de difundir práticas que impeçam ou diminuam a degradação ambiental, ao passo estimular a ampliação de alimentos no ambiente urbano como uma forma saudável de inovar seu espaço.

Palavras-chave: Fazenda vertical. Incentivo Fiscal. Meio Ambiente.

Abstract: The objective of this research is to establish new forms of urban zoning, with an emphasis on establishing socioeconomic activity through the diffusion of vertical farms 
in urban perimeters, and it is up to the Municipality to promote public policies in order to encourage its occurrence, given that it is a a technique that, in addition to establishing an ecologically balanced environment, enables human development. It is understood that a public policy of fiscal incentive especially focused on extrafiscality, allowed the Municipalities to attract companies that have specialty and dominion in this type of practice, growing: vegetables, vegetables and other agricultural activities, by means of the vertical plantation technique, while that these will be forced to insert low-income people into their productive input. According to Article 170 of the Federal Constitution, the primary function of the State, in what concerns the economic order, is to establish a development of the economy emphasizing the value of human labor and free initiative, in order to ensure a dignified coexistence between justice social, environmental protection in line with public policies to boost the economy. Therefore, it is more appropriate to encourage economic agents to disseminate practices that prevent or reduce environmental degradation, while encouraging the expansion of food in the urban environment as a healthy way of innovating their space.

Keywords: Vertical Farm. Fiscal Incentive. Environment. 


\section{INTRODUÇÃO}

Seguindo uma tendência mundial impingida nas conferências internacionais que trataram especificamente sobre o tema: Meio Ambiente, a Constituição Federal de 1988, em seu artigo 225, traçou capítulo visando a proteger, intransigentemente, para defesa das gerações atuais, bem como das futuras, definindo uma política proativa no sentido de abarcar a proteção ambiental como um dos ideais estabelecidos pelo Estado Brasileiro, tal fato pode ser constatado no conteúdo do artigo 225 o qual traz proposições - algumas alcançando a envergadura de princípios, tais como: meio ambiente ecologicamente equilibrado, prevenção, precaução, dever das autoridades de proteger e preservar o meio ambiente, dever de junção dos estudos de impactos ao meio ambiente, dever do poluidor de reparar o dano ambiental, além da precaução quanto ao gerenciamento de risco. Ao destrinchar todos esses elementos percebe-se que o objetivo é amparar o direito, no sentido de impedir ou reprimir os sujeitos que, por ventura, não se enquadrem no ideal protecionista consagrado na $\mathrm{CF}$.

Winter (2005, p. 123) lembra que a Constituição Brasileira é um dos ordenamentos mais celebrados no mundo, em matéria de direito ambiental, à medida que resguardou um capítulo especifico para tratar exclusivamente do tema, diferente de outras constituições, como por exemplo a da Alemanha, que possui apenas um dispositivo disciplinando ações relacionadas ao meio ambiente. Precisamente o artigo $20^{\circ}$ da Constituição Alemã aponta a defesa do Estado relacionado a todas as condições de vida; contudo, todos os princípios e regras cuja finalidade é proteger o meio ambiente têm como anteparo a sanção como forma para se concretizarem os anseios apontados nos ordenamentos.

Entretanto, para impulsionar a proteção ambiental, defende-se que seria de extrema valia correlacionar proteção ambiental a políticas públicas de impulso à economia, para condicionar dois interesses primazes do Estado: a proteção ao meio ambiente na formação do desenvolvimento econômico e a implementação de uma política pública que incremente a economia, por meio do incentivo fiscal; isto é, instigar o produtor, por meio da renúncia fiscal, a proteger o meio ambiente, fazendo a girândola da riqueza circular, especialmente em regiões mais carentes do país.

Nesse diapasão, embora o futuro esteja suscetível a presságios catastróficos que difundem a escassez de toda natureza, especialmente de alimentos, DIAMANDIS e KOTLER (2012, p.27) tem posição contrária a este tese no sentido de entender que o processo de desenvolvimento humano esteja atrelado à tecnologia, cujos processos poderão desencadear práticas proativas capazes de solucionar tais "problemas".

Por tal razão os autores alegam que a sociedade não está em processo acelerado de disseminação, ao contrário está em fase de prosperidade através de práticas revolucionárias que mudarão sensivelmente a forma da sociedade conduzir seus desígnios. Logo, a tecnologia poderá permitir viver-se em abundância, na perspectiva de uma vida que promova preencher as necessidades básicas das pessoas. A propósito, DIAMANDIS e KOTLER (2012, p.27) traçam uma pirâmide de abundâncias divididas em três níveis, sendo a base formada por comida, água, 
abrigo e outras preocupações de sobrevivência básica; o meio dedicado aos catalisadores de mais crescimento, como energia abundante, oportunidades educacionais e acesso a informação global, enquanto o pícaro da pirâmide ficaria reservado à liberdade e a saúde.

Inegavelmente, o aumento sensível da população mundial, especialmente nas grandes cidades, desencadeia uma preocupação: será que o ser humano tem aparato suficiente para produzir alimentos em altíssima escala para amparar a todos? Atualmente, em virtude do aquecimento global as plantações sofrem com condições climáticas hostis, a escassez exponencial da água, além da utilização agressiva de pesticidas ou agentes biológicos para combater pragas que naturalmente se formam para se alimentar das plantações.

$\mathrm{Na}$ vereda dessas percepções, a fazenda vertical aparece como uma excelente alternativa para estabelecer o desenvolvimento sustentável na área urbana com instrumentos cujo norte firme a proteção ao meio ambiente, o desenvolvimento humano com a difusão do emprego e a adoção da função social urbana no intuito que construções abandonadas sejam reutilizadas em prol da coletividade.

\section{PLANTAÇÕES VERTICAIS.}

A técnica das plantações verticais começou na Segunda Guerra Mundial quando as tropas das Forças Armadas norte-americanas começaram a fazer experimentos hidropônicos em larga escala na Ilha Ascenção no Atlântico Sul e posteriormente em Iwo Jima e no Japão. DIAMANDIS e KOTLER (2012, p.135) lembram que no ano de 1983, Richard Stoner descobriu ser possível plantar acima do solo, alimentando os componentes através de uma névoa rica em nutrientes. Surge um novo processo de cultura que espanca o método tradicional, denominando-a de: aeroponia ou hidroponia.

Posteriormente, DESPOMMIER (2010, p.p. 164-169) dispôs que a adoção dessa técnica poderia revolucionar agricultura tradicional. Para o autor, o sistema convencional de agricultura consome $70 \%$ (setenta por cento) da água do planeta, ao passo que não é capaz de firmar um índice de eficácia no tocante a produção, ao contrário da técnica da aeroponia ou hidroponia que, ao invés de consumir $70 \%$ (setenta por cento) de água, consome apenas $6 \%$ (seis por cento) com eficácia de 100 \% (cem por cento) na produção; ademais, a técnica hidropônica tem outro fator decisivo: qualquer local pode ser utilizado para difusão de sua técnica, logo a escassez ou abundância da luz solar é totalmente despicienda, haja vista que as plantações verticais deverão ser projetadas para captar o máximo de luminosidade; da mesma forma, solos inférteis não serão empecilhos para sedimentação desta tecnologia. Ventos e outros infortúnios climáticos também não serão problemas.

Tendo em vista que os nichos populacionais se encontram nas grandes cidades, seria de bom alvitre que os Municípios criassem políticas públicas no sentido de impulsionar esta técnica, atraindo investidores que possam difundi-las sob a condição de treinar e contratar pessoas de baixa renda gerando empregos. Destarte, o Estado em um mesmo processo político: reorganizaria áreas 
urbanas abandonadas como preconiza o artigo 182 da $\mathrm{CF}^{1}$, através da arrecadação de imóveis abandonados, consoante dispõe a Lei $n^{\circ} 13.465 / 2017$, por meio do artigo $64, \S 1^{\text {o }}$, seguindo o procedimento definido no artigo $64, \S \S 2^{\circ}$ e $3^{\circ}$, na qual permite ao Município reutilizar o imóvel arrecadado em prol da coletividade nos moldes dos artigos $64, \S 4^{\circ}$ e 65 da referida legislação ${ }^{2}$, ao passo que se produziria verduras e legumes sem a adição de agrotóxicos ou modificação genética, gerando nas divisas urbanas uma nova forma de incrementar a economia sem o processo agressivo da industrialização. DIAMANDIS e KOTLER (2012, p.137) aduzem que um quarteirão desta técnica é capaz de alimentar 50 mil pessoas ao ano, logo a construção de cento e cinqüenta unidades alimentaria uma megalópole da dimensão de Nova Iorque. Além disso, a adoção da fazenda vertical reduziria os custos de transporte e logística, dado que suas instalações estariam localizadas na vizinhança imediata dos consumidores.

\section{A IMPORTÂNCIA DO DESENVOLVIMENTO DA SUSTENTABILIDADE COMO MÉTODO PARA DIFUSÃO DOS DIREITOS HUMANOS.}

Como a proteção e a preservação do meio ambiente são extensões do princípio universal de proteção à dignidade da pessoa humana, pois sem um meio ambiente aprazível e adequado à sobrevivência, a vida humana na terra ficaria seriamente comprometida, percebe-se que sua cultura protecionista não se restringe a um direito meramente autônomo. Canotilho (2010, p. 11) lembra que a Constituição da República Portuguesa há muito inseriu o meio ambiente, sadio e ecologicamente equilibrado (art. 66. ${ }^{\circ}$ ), como direito constitucional fundamental, com o escopo de sedimentá-lo na qualidade alinhada a direito fundamental.

Por isso que na lição de Santilli (2005, pp. 40/41), o socioambietalismo passou a representar uma alternativa ao conservadorismo preservacionista, ou movimentos ambientalistas tradicionais, mais distantes dos movimentos sociais e das lutas políticas por justiça social, e cética quanto às populações tradicionais no engajamento da conservação da biodiversidade, pois os modelos

1 Art. 182. A política de desenvolvimento urbano, executada pelo Poder Público municipal, conforme diretrizes gerais fixadas em lei, tem por objetivo ordenar o pleno desenvolvimento das funções sociais da cidade e garantir o bemestar de seus habitantes. (BRASIL, 1988)

2 Art. 64. Os imóveis urbanos privados abandonados cujos proprietários não possuam a intenção de conservá-los em seu patrimônio ficam sujeitos à arrecadação pelo Município ou pelo Distrito Federal na condição de bem vago.

$\S 1^{\circ} \mathrm{A}$ intenção referida no caput deste artigo será presumida quando o proprietário, cessados os atos de posse sobre o imóvel, não adimplir os ônus fiscais instituídos sobre a propriedade predial e territorial urbana, por cinco anos.

$\S 2^{\circ} \mathrm{O}$ procedimento de arrecadação de imóveis urbanos abandonados obedecerá ao disposto em ato do Poder Executivo municipal ou distrital e observará, no mínimo:

I - abertura de processo administrativo para tratar da arrecadação;

II - comprovação do tempo de abandono e de inadimplência fiscal;

III - notificação ao titular do domínio para, querendo, apresentar impugnação no prazo de trinta dias, contado da data de recebimento da notificação.

$\S 3^{\circ} \mathrm{A}$ ausência de manifestação do titular do domínio será interpretada como concordância com a arrecadação.

$\S 4^{\circ}$ Respeitado o procedimento de arrecadação, o Município poderá realizar, diretamente ou por meio de terceiros, os investimentos necessários para que o imóvel urbano arrecadado atinja prontamente os objetivos sociais a que se destina.

Art. 65. Os imóveis arrecadados pelos Municípios ou pelo Distrito Federal poderão ser destinados aos programas habitacionais, à prestação de serviços públicos, ao fomento da Reurb-S ou serão objeto de concessão de direito real de uso a entidades civis que comprovadamente tenham fins filantrópicos, assistenciais, educativos, esportivos ou outros, no interesse do Município ou do Distrito Federal. (BRASIL, 2017) 
de proteção ambientalistas tradicionais tendem a se inspirar nos movimentos de preservação ambiental importados de países de primeiro mundo e estão longe das pressões típicas dos países desenvolvidos, em que suas populações pobres, oprimidas por situações econômicas que gravitam na subsistência optam, irremediavelmente, por depredar o meio ambiente e toda diversidade nele impingida em vez de protegê-lo.

Já a alternativa preservacionista tenta, com fundamento na dignidade da pessoa humana, estabelecer parâmetros de proteção ao meio ambiente, no intuito de que as futuras gerações possam gozar de um ambiente mais condizente com os seus anseios. Para Grau (1995, p. 49), a divisão retro proposta não é estanque, uma vez que permite um entrelaçamento dos seus conceitos na busca de uma proteção ideal ao meio ambiente, haja vista que a intervenção econômica prevista na Constituição Federal, em seu artigo 170, VI, estabelece três elementos: a) participação; b) direção; e c) indução.

A inserção do respeito ao meio ambiente no ordenamento jurídico brasileiro, alcança o grau máximo, sendo considerado um dos princípios basilares da atividade econômico-financeira e encontra sucedâneo também no ordenamento jurídico ordinário no artigo $2^{\circ}$, caput, da Lei $\mathrm{n}^{\mathrm{o}}$ 6.938/81, a qual estabelece que a Política Nacional do Meio Ambiente tem por objetivo a preservação, melhoria e recuperação da qualidade ambiental propícia à vida, visando a assegurar no país condições ao desenvolvimento socioeconômico aliado aos interesses da segurança nacional e à proteção da dignidade da vida humana, haja vista que ambos os temas caminham em perfeito sincronismo (BRASIL, 1981) Sarlet (2006, p. 60) salienta que se trata de uma qualidade intrínseca e distintiva de cada ser humano, que o faz merecedor do mesmo respeito por parte do Estado e da comunidade; que propicie garantir condições existenciais mínimas para uma vida saudável, além de proporcionar e promover a participação ativa nos desígnios da existência e da vida em comum com os demais seres humanos, situados na esfera territorial e extraterritorial.

Com a massificação do consumo e seu apelo existencial, somado a uma massificação social que cresce exponencialmente, vivenciar uma qualidade de vida condigna passou a ser um ideário primaz do homem, criando, como lembra Antunes (2013, p. 17), uma nova realidade calcada na bivalência entre uma conscientização que aloca o meio ambiente saudável como um direito fundamental de escol, havendo aqueles que entendem ser o meio ambiente algo substancial, mas não deve ser inserido no campo dos direitos sociais e individuais, sob pena de seu entrechoque impedir o desenvolvimento econômico de uma determinada região.

A Constituição Econômica surgiu com o Estado Social, com o propósito de regulamentar a economia, ao passo que exerce uma atividade de controle ante abusos que podem ser desencadeados pela iniciativa privada no exercício de sua atividade.

Por isso que Pagliarini e Bastos (2011, p. 47) entendem que o princípio do meio ambiente deverá encontrar possibilidades fáticas e jurídicas para sua concretização. Quanto à possibilidade jurídica, nota-se que o meio ambiente traz limites à atividade econômica, no sentido de ditar para esta o seu respeito, que muitas vezes exige abrir mão de parcela de seu lucro, mas, como lembra Tavares (2003, p. 196), nem o desenvolvimento há de ser impedido pela proteção ambiental, nem 
o meio ambiente poderá ser desconsiderado pelo desenvolvimento econômico, torna-se, portanto, indispensável ao intérprete da Constituição ponderar entre os valores da iniciativa privada e propriedade e os do meio ambiente, cujo resultado deve ser a máxima efetividade desses princípios.

Nessa perspectiva, Wolkmer (2010, p. 25) afirma que, para o Direito ser utilizado com o objetivo de proteger o homem, seu alcance deve ser o mais abrangente possível nos ordenamentos, mas nada impede que novos cenários ligados à natureza humana sejam construídos no encalço de proteger o cenário humano. Nesse sentido, o Estado pode funcionar como um catalisador proativo regulando a atividade econômica, através das funções de fiscalização, incentivo e planejamento, sendo este determinante para o setor público e indicativo para o setor privado, permitindo e apoiando a criação de legislações que tendam apoiar e estimular o cooperativismo e outras formas de associativismo ${ }^{3}$, logo nada impede que os Municípios possam inserir nas áreas abandonadas e arrecadadas fazendas verticais difundindo esta prática em parceria com todos os empreendedores e com um nível razoável de coesão social.

No Brasil, ao se referir à sustentabilidade, sua conotação ganha status de princípio constitucional recepcionado pela Constituição e que determina, independentemente de regulamentação legal, com eficácia direta e imediata, a responsabilidade do Estado e da sociedade pela concretização solidária do desenvolvimento material e imaterial, socialmente inclusivo, durável e equânime, ambientalmente limpo, inovador, ético e eficiente, no intuito de assegurar, hoje, o bem-estar físico, psíquico e espiritual, em consonância homeostática com o bem de todos. (BRASIL, 1988).

A noção de sustentabilidade surgiu no sistema legislativo brasileiro para mudar o paradigma do desenvolvimento centrado no mero crescimento econômico, ensejando uma nova visão do sistema econômico que leva a inseri-lo numa cadeia de reações e de processos originada no sistema ecológico, ao qual acaba por retornar, implicando a impossibilidade de o primeiro deles ser visto como um sistema totalmente aberto, tal como tradicionalmente considerado, isto é, um sistema em que se torna irrelevante o conhecimento da origem e destino dos materiais e energia nele utilizados e dele extraído e renovado.

Contudo, além disso, Bursztyn e Bursztyn (2012, p.165) lembram que as políticas ambientais, além de ser um processo pedagógico, permitem a inovação no que tange a matérias e decisões que, na prática, visem a reverter a lógica predatória do processo produtivo, por meio dos incentivos - no caso estudado deduções tributárias. A propósito, vale lembrar que programar o incentivo fiscal como forma de política pública de proteção ao meio ambiente não é algo surreal, tampouco sem respaldo legal, haja vista que seus implementos práticos podem ser retirados do artigo 225, $\S 1^{\circ}$, I, da Constituição Federal - que assegura a todos (geração presente e futura) um meio ambiente equilibrado -, permite o incentivo a pesquisas de tecnologias tendentes ao

\footnotetext{
3 Art. 174. Como agente normativo e regulador da atividade econômica, o Estado exercerá, na forma da lei, as funções de fiscalização, incentivo e planejamento, sendo este determinante para o setor público e indicativo para o setor privado.

$\S 1^{\circ}$ A lei estabelecerá as diretrizes e bases do planejamento do desenvolvimento nacional equilibrado, o qual incorporará e compatibilizará os planos nacionais e regionais de desenvolvimento.

$\S 2^{\circ}$ A lei apoiará e estimulará o cooperativismo e outras formas de associativismo. (BRASIL, 1988)
} 
uso racional e à proteção aos recursos ambientais. Inserir a dedução de impostos como meio de incentivar o empresariado a proteger o meio ambiente, ou, na cadência da sua cadeia produtiva, degradar em uma escala reduzida, propicia o equilíbrio necessário para aplicação prática do desenvolvimento sustentável sem que isso infrinja implicar a igualdade tributária para outros seguimentos da sociedade, pois como lembra Alexy (2008, pp.429-430), se houver uma razão suficiente para o dever de um tratamento desigual, então, o tratamento desigual é obrigatório, pois esses direitos abstratos conduzem a direitos concretos muito diferentes, logicamente buscando-se um propósito adequado à sociedade, à proteção da natureza e à preservação da vida em sociedade, em especial os direitos humanos.

Silva (2013, p.235) destaca que a compatibilização do desenvolvimento econômicosocial com a preservação da qualidade do meio ambiente e do equilíbrio ecológico é o primeiro objetivo indicado, sendo um critério de orientação para ação governamental e uma meta a ser atingida. Significa dizer que a Política Nacional de Meio Ambiente não admite o desenvolvimento com sacrifício da qualidade do meio ambiente e do equilíbrio ecológico, assumindo a política do equilíbrio conciliando os dois vieses: crescimento econômico e proteção ambiental, considerando o uso racional dos recursos naturais e a garantia da permanência da política de produção renovável.

Trata-se de um dos temas pulsantes para deliberação do homem moderno, visto que envolve sua sobrevivência e das futuras gerações, logo sua implementação não é uma mera escolha do administrador, mas uma imposição em prol dos interesses da sociedade; logo, sua implantação não pode ficar a mercê das burocracias que povoam a administração pública e fiscal brasileira, cabendo ao estado deliberar sobre a conveniência e oportunidade na sua integração.

Embora, paulatinamente, o legislador brasileiro venha entendendo que a política pública de proteção ambiental pode perpassar pelos incentivos tributários, pela retumbante eficácia, partindo do seguinte pressuposto: se forem concedidos benefícios fiscais a quem exerce atividade que, na sua cadeia final, irremediavelmente causa danos ao meio ambiente, a partir do instante que se concede o beneficio a tendência é a minimização máxima da agressão ou uma exponencial diminuição.

A CF, nos seus artigos $170, \mathrm{VI}, 174, \S 1^{\circ}$ e $225, \mathrm{~V}^{4}$, prevê o direito ao desenvolvimento sustentável como fundamental ao cidadão brasileiro, o qual compreende o consumo racional e garantidor da qualidade de vida das gerações presentes e futuras como uma de suas facetas; aloca, ainda, no artigo 174 , caput e $174, \S 1^{\circ}$ da $C^{5}$ que o agente normativo e regulador da atividade

4 Art. 170 A ordem econômica, fundada na valorização do trabalho humano e na livre iniciativa, tem por fim assegurar a todos existência digna, conforme os ditames da justiça social, observados os seguintes princípios:

$[\ldots]$

VI - defesa do meio ambiente, inclusive mediante tratamento diferenciado conforme o impacto ambiental dos produtos e serviços e de seus processos de elaboração e prestação; (Redação dada pela Emenda Constitucional n 42 , de 19.12.2003);

[...] BRASIL, 1988)

Art. 174, [...]

$\S 1^{\circ}$ A lei estabelecerá as diretrizes e bases do planejamento do desenvolvimento nacional equilibrado, o qual incorporará e compatibilizará os planos nacionais e regionais de desenvolvimento [...] (BRASIL, 1988).

Art. 225, [...]

V controlar a produção, a comercialização e o emprego de técnicas, métodos e substâncias que comportem risco para a vida, a qualidade de vida e o meio ambiente. (BRASIL, 1988)

5 Art. 174 Como agente normativo e regulador da atividade econômica, o Estado exercerá, na forma da lei, as funções 
econômica exercerá, na forma da lei, as funções de fiscalizador, planejador, e incentivador de práticas que tendam a alicerçar o desenvolvimento nacional equilibrado.

Nesse aspecto, não se pode olvidar que a CF brasileira, ao erigir a Dignidade da Pessoa Humana como seu corolário o fez dentro de uma compreensão antropocentrista, colocando o Ser Humano no epicentro das preocupações que esse Texto Magno resolveu tutelar à garantia do desenvolvimento nacional (artigo $3^{\circ}$, II, da CF) e à erradicação da pobreza e da marginalização (artigo $3^{\circ}$, III, CF) ${ }^{6}$, ambos apanágio da prevalência dos valores do trabalho e da livre iniciativa (artigo $1^{\circ}$, IV, da CF), objetivos fundamentais da República.

\subsection{A adoção da extrafiscalidade como meio para implementação das fazendas verticais nos perímetros urbanos.}

Uma das soluções para os problemas ambientais, segundo Coelho (2010, p. 104), é a promoção de valores sociais que integrem o conhecimento e a vivência de um sistema vivente organizado em função da vida e não de argumentos culturais e econômicos de dominação e destruição, segundo o qual a prática da 'vivência biocêntrica' nos espaços profissionais propicia a sensibilização e o desenvolvimento de habilidades, com foco no papel profissional e na dinâmica das relações no contexto de trabalho, com vistas a facilitar a busca por caminhos que lhes permitam resolver os problemas e alcançar o necessário equilíbrio.

Realça Mello (2013, p. 34), que as normas promocionais se corporificam como normas jurídicas que, ao invés de estabelecerem tão somente sanções ou coações para fazer valer suas imposições, inclinam-se no sentido de empreender outros mecanismos de controle à lei, especialmente que visem a premiar aqueles que estão de acordo com a norma vigente, para garantir que uma das funções precípuas das normas jurídicas: a adaptação social do homem punir, proibir, obrigar, permitir - estaria à disposição para educar os comportamentos humanos, da mesma maneira que a premiação estaria submetida à mesma função: moldar o comportamento humano à guisa dos seus valores, principalmente os preconizados pela Constituição Federal, como bem assevera Bercovici (2005, p. 148), uma vez que o constitucionalismo social do Século XX está norteado pela adoção da ordem econômica e social, na perspectiva de uma Constituição Econômica ou Dirigente.

Por tal razão, seria de suma importância que os Municípios traçassem legislações que pudessem traçar políticas públicas coincidindo práticas sustentáveis com inclusão social sedimentado no tripé: terra, capital e trabalho, numa perspectiva local e mundial como ensina Comparato (1990, p.102).

\footnotetext{
de fiscalização, incentivo e planejamento, sendo este determinante para o setor público e indicativo para o setor privado.

$\S 1^{\circ}$, da CF: A lei estabelecerá as diretrizes e bases do planejamento do desenvolvimento nacional equilibrado, o qual incorporará e compatibilizará os planos nacionais e regionais de desenvolvimento (BRASIL, 1988).

6 Art. $3^{\circ}$ Constituem objetivos fundamentais da República Federativa do Brasil:

I - construir uma sociedade livre, justa e solidária;

II - garantir o desenvolvimento nacional;

III - erradicar a pobreza e a marginalização e reduzir as desigualdades sociais e regionais, (BRASIL, 1988).
} 
Para viabilizar esse ideal social, o Estado passou a ser não mais parte coadjuvante, mas, integrante, pois, embora a sociedade clame por tributos mais justos, ponto nodal reivindicado de modo assente é a forma como os tributos podem melhorar a vida de todos os cidadãos.

Percebe-se que a adoção da política pública está imbricada dentro do conjunto de ações político - governamentais cujo intuito é galgar o bem estar social coletivo, cuja iminência dependerá da prioridade assumida pelo agente governamental ao traçar sua estratégia. Nesse contexto, afere Krell (2002, p. 99), um dos pontos culminantes nas agendas desenhada pelos estados é traçar estratégias que tendam a proteger o meio ambiente, em combate à degradação instaurada e intensificada pela economia neoliberal que disseminou o anseio do consumo inveterado e predatório, cujo efeito se desencadeia na utilização sem critérios e remissões dos recursos minerais.

Dessa forma, a intervenção do Estado, mediante políticas públicas que venham tencionar e impulsionar a proteção ambiental, seria extremamente salutar, quer no aspecto de incutir uma ampla conscientização da sociedade, bem como no sentido de entender o meio ambiente como algo incrustado à sua sobrevivência, criando políticas de incentivo no intuito de, na fonte, impedir que a degradação ocorra ou, ao menos, seu exercício minimizado para que se tenha uma possibilidade de renovação do ecossistema.

O critério econômico destaca a necessidade do desenvolvimento intersetorial equilibrado, a segurança alimentar, a capacidade de modernização contínua dos instrumentos de produção e razoável nível de autonomia na pesquisa científica e tecnológica, coadunando às disposições plasmadas no artigo 170, VI, da CF que procura conciliar atividade econômica e defesa do meio ambiente por meio de tratamento diferenciado às empresas que, no processo de elaboração e prestação das suas atividades fins, procuram proteger ou atenuar os impactos junto ao meio ambiente.

Nessa perspectiva, o direito tributário ambiental ingressa no sistema jurídico brasileiro jungido de um novo objetivo: elaborar medidas de proteção aos recursos naturais existentes na sociedade, assim como sua manutenção e conservação, com anteparo nos princípios ambientais, tributários, constitucionais, instrumentais e particulares, que valorem a liberdade, a justiça, a segurança jurídica e a solidariedade, cujo interesse retumbante seria promover o desenvolvimento sustentável, com assento na preservação do potencial da natureza para a produção de recursos renováveis; assim, as medidas extrafiscais são consideradas como forma de se obter uma ordem social mais justa e eficiente encontrando guarida no artigo 43, $\S 2^{\circ}$, II, da Constituição Federal ${ }^{7}$ o qual permite os incentivos por meio de isenções, reduções ou deferimento temporário de tributos federais devidos por pessoas físicas ou jurídicas.

Carrazza (2008, p. 690) alerta que conceder incentivos fiscais para proteção do meio ambiente não é um alvedrio do legislador infraconstitucional, visto que todas as disposições retro fustigadas têm amparo na legislação constitucional, logo são de índoles de afetação direta, 7 Art. 43 Para efeitos administrativos, a União poderá articular sua ação em um mesmo complexo geoeconômico e social, visando a seu desenvolvimento e à redução das desigualdades regionais. $[\ldots]$

$\S 2^{\circ}$ - Os incentivos regionais compreenderão, além de outros, na forma da lei:II - juros favorecidos para financiamento de atividades prioritárias;

[...]. (BRASIL, 1988). 
e não meros programas de ação a serem desenvolvidos e adotados pelos governantes. Por isso, a dedução de imposto para incentivar empresas que desenvolvem as fazendas verticais em nível de produção e pesquisa poderia mudar drasticamente o cenário do espaço urbano, produzindo em escala exponencial verduras, legumes e outras culturas, sem o aditivo de pesticidas ou outras substancias danosas ao ser humano, à medida que permitiria as pessoas de baixa renda destas cidades trabalharem nestas empresas e poderem se soerguer economicamente, além de disseminar o consumo sustentável e absolutamente natural.

Embora a competência tributária seja indelegável, intransferível, inalterável e irrenunciável, como dispõe artigo $8^{\circ}$ do Código Tributário Nacional (CTN), o exercício da competência tributária pode ser considerado facultativo, a mercê do plano da conveniência incidente em cada ente tributante. Inobstante, exista posicionamento diverso, apreendido no art. 11 da Lei de Responsabilidade Fiscal (LC n. 101/2000), segundo o qual, no plano de gestão fiscal da pessoa política, deve haver a instituição de "todos" os tributos que compete à entidade, sob pena de sanções, e, no caso de inação por parte do gestor público incidir na prática de evasão fiscal lícita, ou seja, quando a legislação tributária permite a redução ou supressão do tributo a pagar, por exemplo, através de benefícios fiscais (isenções ou imunidades), conforme (art.11, parágrafo único) (BRASIL, 2000).

Entretanto, alerta Sabbag $(2009$, 389), a interpretação do dispositivo merece a devida cautela, pois a concepção extraída da vontade do legislador é estimulação de tributos economicamente viáveis.

Em relação à instituição de incentivos fiscais visando a proteger o meio ambiente, percebese uma coerência insofismável, pois, embora o agente deixe de auferir as vantagens econômicas pela omissão de receita, por outro lado passa a ter um instrumento assaz eficaz na proteção de um interesse difuso e em consonância com os princípios consagrados na $\mathrm{CF}$, em especial, o princípio da eficácia integradora, difundida por Mendes, Coelho e Branco, (2008, p. 136), que orienta o aplicador da Constituição no sentido de, ao construir soluções para os problemas jurídico-constitucionais, procure dar preferência àqueles critérios ou pontos de vista que favoreçam a integração social ou a unidade política, porque, toda Constituição necessita produzir e manter a coesão sociopolítica, como pré-requisito ou condição de viabilidade de qualquer sistema jurídico.

Por essa razão, lembra Carrazza (2008, p. 687), que os instrumentos tributários postos à disposição do sistema podem e devem ser utilizados para fins de defesa do meio ambiente, pois a atividade financeira - inserindo-se a tributária, não é um fim em si mesmo; logo, sendo um mandamento meramente instrumental, dado que o interesse precípuo do Estado é subsidiar os agentes por meio de incentivos pecuniários no sentido de atingir as necessidades prementemente apontadas na Constituição.

O meio ambiente se qualifica como um fim juridicamente relevante, e pode ser definido como um objeto qualificado transformando-se em "fim" a ser atingido impondo e permitindo condutas que visem a sua realização ou proteção, e no campo teleológico podem se concretizar através de comportamentos que preservem determinado estado de coisas. Assim, lembra Canotilho 
(2010, p. 10), adotar um novo método de proteção ao meio ambiente, ao lado dos métodos tradicionais de ordem, permissão e proibição, como, por exemplo, a sanção, pode ensejar novas tentativas de se obter o sucesso almejado; sendo assim, incentivar as diversas formas de "estímulos" ou "incentivos" destinados a promover programas de sustentabilidade permite que o Estado continue praticando seu mister de cobrar as exações devidas, dentro de uma nova lógica, dessa vez incutindo aos contribuintes uma missão de preservar um ambiente ecologicamente equilibrado.

Carrazza (2008, p. 688) aduz que há muito tempo se percebeu que na desoneração em beneficio do bem comum, há uma sensação, naquele que exerce o dever de condução dos negócios em paridade com os anseios sociais; ao passo que, lembra o autor, a partir do instante em que o Estado se vale da extrafiscalidade para tentar estimular comportamentos, quer pela ação, quer pela inação dos seus contribuintes, via de regra, ele consegue obter melhores resultados do que aqueles firmados pelo meio usual de arrecadação e depois de destinação dos impostos.

Scaff (2005. p.746) entende que, ao se interpretar aberta e sistemática a Constituição Federal, não se pode olvidar a realidade do uso do direito tributário para a consecução de políticas públicas necessárias ao desenvolvimento nacional, fazendo com que o Direito cumpra um novo papel diverso daquele tradicional, de instrumento de segurança das relações sociais. Com a dedução de impostos, a resposta social é imediata, pois o contribuinte somente fará jus aos incentivos estampados na legislação, se por ventura se portar daquela maneira protetiva delineada.

Sobreleva apontar que não há no Texto Constitucional dispositivo que arregimente a utilização dos tributos para fins extrafiscais, mas seu artigo 155, I estabelece um precedente que implicitamente reconhece a faculdade que o Estado tem de utilizar as exações como meio de promover o equilíbrio do desenvolvimento socioeconômico; visa-se, consequentemente, a reduzir as retumbantes desigualdades entres as regiões do país e a embaraçosa e sistêmica pobreza que assola o país, conforme artigo $3^{\circ}$, III, CF.

Nesse diapasão, as empresas desempenham papel substancial para a sociedade, uma vez que produzem estímulos às atividades econômicas, por meio da produção de bens e serviços, propiciando uma melhoria na qualidade de vida das pessoas e gerando posto de trabalho; dessa forma incentivar as empresas a alavancar suas atividades não é um ato benévolo por parte do Estado, ao contrário, deveria ser uma política pública que, uma vez sedimentada, renderia resultados extremamente positivos àquela região atingida, pois faria a riqueza circular com mais ênfase, incrementando a economia local.

\subsection{Incentivos Fiscais x Lei de Responsabilidade Fiscal}

Vale asseverar que os benefícios fiscais não se encontram na área do direito tributário, essencialmente. $\mathrm{O}$ direito econômico é uma área típica que rege a atividade fiscal, por isso que o $\S 1^{\circ}$, do artigo 14 da Lei de Responsabilidade Fiscal ${ }^{8}$ estabelece um conceito jurídico-formal

8 Art. 14 - A concessão ou ampliação de incentivo ou benefício da natureza tributária da qual decorra renúncia de receita deverá estar acompanhada do impacto-financeiro no exercício em que deva iniciar sua vigência e nos dois seguintes, atender ao disposto na lei de diretrizes orçamentárias e a, pelo menos, uma das seguintes condições:

$\S 1^{\circ}$. A renúncia compreende anistia, remissão, subsídio, crédito presumido, concessão de isenção em caráter não 
atinente aos benefícios fiscais. Assim, a LC n. ${ }^{\circ}$ 101/2000, trata os "benefícios fiscais" como "renúncia de receita" por parte do Estado, mas a concepção que deve enveredar o administrador tem sustentáculo no desenvolvimento humano.

No caso dos benefícios fiscais para implementação de ações em prol da proteção ao meio ambiente, percebe-se que a abdicação do Fisco não pode ser encarada como um malefício, haja vista que o retorno positivo de uma região com índices de poluição reduzidos, e com a inserção de outro mecanismo de produção de energia, em consonância com a sustentabilidade, são elementos que devem converter a renúncia do Estado em um forma de investimento, nos moldes do capital humano, visto que sua aplicação favorece determinados setores, atividades, regiões do País ou agentes da economia, no atendimento de determinada política pública social ou econômica, produzindo os mesmos resultados econômicos da despesa pública.

Por essa razão que Henriquez (2010, p. 16) estabelece ser possível ligar os conceitos de benefício fiscal e de despesa pública, criando uma figura financeira nova: o gasto tributário.

No contexto atual do direito tributário, pode-se atestar que a concessão de benefícios fiscais visando à proteção do meio ambiente mostra-se como uma medida interventiva do Estado, no sentido de consagrar a proteção de um direito fundamental de alto vulto, dado que sua incidência transpõe a esfera da territorialidade. $O$ direito tributário se soma a conceitos alinhados no direito econômico, cujo ramo procura ampliar o exercício da função promocional dos direitos, por meio dos benefícios fiscais, cujo fundamente se alinha a um tratamento tributário benéfico "diferenciado" ou "discriminado". Dessa soma, surge uma nova concepção para orientar a atividade empresarial. Antes o empresariado somente se volvia no binômio custo/beneficio, hoje, essa concepção mostrase defasada pela inserção do meio ambiente como suporte inexorável para o desenvolvimento econômico sustentável, criando um tripé calcado no custo/beneficio/meio ambiente. Com a adoção do incentivo fiscal como meio de instituir uma política de proteção ao meio ambiente, o discurso passou a ser mais atrativo, dando possibilidades críveis para a adesão do empresariado.

Percebe que o uso de tributos como matriz ambiental não traz qualquer contrariedade à disposição constitucional. No Brasil, a tese da tributação ambiental ganhou corpo na doutrina, vez que a sanção positiva ou premial poderia ser utilizada com mais contundência na consecução de políticas públicas de proteção (eficaz) ao meio ambiente, mas alguns entraves burocráticos impedem a disseminação dessa ideia, tais como: as iniciativas legislativas ambientais e estaduais e a falta de interesse da classe política, em especial do Poder Executivo, que associa o incentivo fiscal meramente como a não injeção de recursos nos cofres públicos, sem perceber os benefícios que sua prática desencadeia.

\section{CONCLUSÕES}

Diante das exposições destacadas neste estudo, passa-se a concluir que o Brasil, erigiu o contribuições, e outros benefícios que correspondam a tratamento diferenciado. (BRASIL, 2000). 
meio ambiente, como direito similar aos individuais fundamentais. Neste contexto, a CF, em seu artigo 225, traçou capítulo no intuito de disciplinar a defesa do meio ambiente visando a proteger as gerações atuais e as futuras através das seguintes proposições: meio ambiente ecologicamente equilibrado, prevenção, precaução, dever das autoridades de proteger e preservar o meio ambiente, dever de junção dos estudos de impactos ao meio ambiente, dever do poluidor de reparar o dano ambiental e a precaução no gerenciamento de risco.

Para que a meta constitucional se concretize, o Estado correlacionou a proteção ambiental as políticas públicas de impulso à economia, permitindo que a economia volte a modificar suas matrizes de desenvolvimento por meio do incentivo fiscal, através da instigação do produtor, mediante a renúncia fiscal, gerando uma nova forma de alinhavar a sanção como um fator se inserção, para tanto, a doutrina enumerou esta tendência como "sanção premial".

Especialmente para consecução das fazendas verticais, sua construção para se mostrar eficaz no âmbito do Município seria calcada na concreção de políticas públicas tendentes a sensibilizar os gestores públicos, a concederem isenção de imposto, além da utilização de áreas inutilizadas no centro urbano, para sua instalação, manutenção e fomento a pesquisa, em contrapartida estas empresas difundiriam sua tecnologia no sentido de gerar o plantio de verduras sem a adição de substâncias danosas ao organismo humano, ao passo que poderia ser adotado como um forte elemento de inserção social, uma vez que os gestores poderiam determinar que a concessão do benefício fosse atrelada a contratação de pessoas de baixa renda, preferencialmente da região na qual a estrutura fosse construída. Com o advento desta tecnologia, modificar-se-ia o cenário urbano, otimizando os espaços que poderias ter uma finalidade social que tergiversaria com os ideais comuns, gerando uma sensação de bem estar.

\section{REFERÊNCIAS}

ALEXY, Robert. Teoria dos direitos fundamentais. São Paulo: Malheiros Editores, 2008.

ANTUNES, Paulo de Bessa, Direito ambiental, 15. ed.. São Paulo: Atlas, 2013.

BERCOVICI, Gilberto. Constituição econômica e desenvolvimento: uma leitura a partir da Constituição de 1988. São Paulo: Malheiros, 2005.

BONAVIDES, Paulo, Curso de direito constitucional, 28. ed.. São Paulo: Malheiros, 2013.

BRASIL. Constituição da República Federativa do Brasil. Brasília, 05 de outubro de 1988. Disponível em: < http://www.planalto.gov.br/ccivil_03/constituicao/ constituicao.htm>. Acesso em: 11 dez. 2017.

Lei Complementar 101, de 04 de maio de 2000. Estabelece normas de finanças públicas voltadas para a responsabilidade na gestão fiscal e dá outras providências. Disponível em: < http://www.planalto.gov.br/ccivil_03/leis/lcp/lcp101.htm>, Acesso em: 03 dez. 2017. 
Lei no 10.257, de 10 de julho de 2001. (Estatuto da Cidade) Regulamenta os arts. 182 e 183 da Constituição Federal, estabelece diretrizes gerais da política urbana e dá outras providências. Disponível em: <http://www.planalto. gov. br/ccivil/leis/L10257.htm>. Acesso em: 11 dez. 2017.

.Lei no 13.465, de 11 de julho de 2017.Disponível em: < http://www.planalto. gov.br/ccivil_03/_ato2015-2018/2017/lei/113465.htm >. Acesso em: 12.dez.2017

BUCCI, Maria Paula Dallari (Org.). Políticas públicas: reflexões sobre o conceito jurídico. São Paulo: Saraiva, 2006.

BURSZTYN, Maria Augusta e BURSZTYN, Marcel. Fundamentos de política e gestão ambiental: caminhos para sustentabilidade. Rio de Janeiro: Garamond, 2012.

CANOTILHO, José Joaquim Gomes, O princípio da sustentabilidade como princípio estruturante do direito constitucional. Revista de Estudos Politécnicos Polytechnical Studies Review, Vol VIII, $n^{\circ}$ 13, 2010. Disponível em:<http://www.scielo. oces.mctes .pt/pdf/tek/n13/ n13a02.pdf $>$. Acesso em: 24 abr. 2014

CARRAZZA, Roque Antônio, Curso de direito tributário, 24. ed.. São Paulo: Malheiros, 2008.

COELHO, Carla Jeane Helfemsteller. Planejamento ambiental e gestão administrativa. In: COELHO, Carla Jeane Helfemsteller ;MELO, Maria das Dores de Vasconcelos Cavalcanti (org.). Saberes e fazeres da Mata Atlântica do Nordeste: lições para uma gestão participativa. . Recife: Associação para Proteção da Mata Atlântica do Nordeste (AMANE), 2010 (p. 101116).

COMPARATO, Fábio Konder, Para viver a democracia. São Paulo: Brasiliense, 1990.

DIAMANDIS, Peter; KOTLER, Steven. Abundância:o futuro é melhor do que você imagina. São Paulo:HSM Editora, 2012,

DESPOMMIER, Dickson, The Vertical Farm: Feeding the World in the 21st Century. Chicago: ST Martins Press, 2010.

HENRIQUEZ, Élcio Fiori. Os benefícios fiscais no direito financeiro e orçamentário: O gasto tributário no direito brasileiro. São Paulo: Quartier Latin, 2010.

GIDDENS, Anthony. A terceira via: reflexões sobre o impasse político atual e futuro da socialdemocracia. Rio de Janeiro: Record, 1998.

GRAU, Eros, A ordem econômica na Constituição de 1988. 2. ed.. São Paulo: Revista dos Tribunais, 1995.

KRELL, Andreas Joaquim. Direito sociais e controle judicial no Brasil e na Alemanha - Os (des)caminhos de um direito constitucional "comparado". Porto Alegre: Sergio Antonio Fabris, 2002. 
MELLO, Marcus Bernardes de, Teoria do fato jurídico: plano da existência, São Paulo: Saraiva, 2013.

MENDES, Gilmar; COELHO, Inocêncio Mártires; BRANCO, Paulo Gustavo Gonet. Curso de Direito Constitucional. 2 ed. Brasília: Instituto Brasiliense de Direito Público e Saraiva, 2008.

PAGLIARINI, Alexandre; BASTOS, Juliana Cardoso Ribeiro. Uma interpretação constitucional sobre a relação entre economia e direito ambiental. Revista de Direito da Mackenzie, v.5, pp. 37-52, 2011.

internacional dos direitos humanos. Belo Horizonte: Fórum, 2012.

. Teoria geral e crítica do direito constitucional e internacional dos direitos humanos. In: _ _ DIMOULIS, Dimitri (Coord). Direito constitucional

PFERSMANN, Otto, Positivismo jurídico e justiça constitucional no século XX. São Paulo: Saraiva, 2014.

SABBAG, Eduardo de Moraes, Manual de direito tributário, São Paulo: Saraiva, 2009.

SACHS, Ignacy. Caminhos para o desenvolvimento sustentável. Rio de Janeiro: Garamond, 2000.

SANTILLI, Juliana, Socioambientalismo e novos direitos - proteção jurídica da diversidade biológica e cultural. São Paulo; Petrópolis, 2005.

SARLET, Ingo Wolfgang. Dignidade da pessoa humana e direitos fundamentais na Constituição de 1988, 4. ed.. Porto Alegre: Livraria do Advogado, 2006.

SCAFF, Fernando Facury. Tributação e políticas públicas: o ICMS ecológico. In: TORRES, Heleno Taveira (org.). Direito tributário ambiental. São Paulo: Malheiros, 2005.

SILVA, Geraldo Eulálio do Nascimento. Direito ambiental internacional. 2. ed.. Rio de Janeiro: Thex Editora, 2002.

TAVARES, André Ramos. Direito constitucional econômico. São Paulo: Método, 2003.

WINTER, Gerd, A natureza jurídica dos princípios ambientais em direito internacional, direito da Comunidade Européia e direito nacional. In: KISHI, Sandra Akemi Shimada; SILVA, Solange Teles da; SOARES, Inês Virginia Prado. Desafios do direito ambiental no século XXI. São Paulo: Malheiros, 2005.

WOLKMER, Antonio Carlos. Novos pressupostos para a temática dos direitos humanos, In: FLORES, Joaquín Herrera; RUBIO, David Sánchez; CARVALHO, Salo de. Direitos humanos e globalização: fundamentos e possibilidades desde a teoria crítica, $2^{\mathrm{a}}$ ed. - Dados eletrônicos. Porto Alegre: EDIPUCRS, 2010.

Como citar: PAGLIARINI, Alexandre Coutinho. SANTOS, Flávio Adriano Rebelo Bandrão. 
A utilização da fazenda urbana vertical como meio de comentar a sustentabilidade. Revista do Instituto de Direito Constitucional e Cidadania, Londrina, v. 3, n. 1, p. 209-225, jan/jun. 2018.

Recebido em: 10/04/2018

Aprovado em: 25/04/2018 